\title{
Green, Innovative, and Profitable: A Case Study of Managerial Capabilities at Interface Inc.
}

\author{
Tommi Lampikoski
}

\author{
"Since 2003, we've sold over 83 million square yards of ") \\ carpet with no net global warming effect. These climate- \\ neutral carpets, Cool Carpets, have been runaway \\ bestsellers. That's competitive advantage at its best - \\ doing well by doing good.
}

\author{
Ray Anderson (1934-2011) \\ Founder of Interface Inc.
}

\begin{abstract}
This article describes the pioneering green-innovation management practices of a resource-intensive corporation, Interface Inc., which is a globally operating carpet manufacturer. Even during the current economic downturn, many companies remain committed to advancing their green business agendas. However, recent research suggests that most of these companies are far from reaching substantial competitive advantage from this commitment because they lack the connection between their green agendas and core innovation-management activities. This study illustrates how Interface succeeded with radical green innovations by investing in managerial capabilities that allowed it to conduct research, recognize opportunities, and revolutionize the carpeting industry. These capabilities enabled Interface to continuously challenge and disrupt well-established management recipes, existing knowledge, and proven industrial practices, and they enabled it to create a sustainable competitive advantage through a winning portfolio of radical green innovations.
\end{abstract}

\section{Introduction}

Going green can be a magnificent business opportunity and a potential source of competitive advantage, but it also presents a managerial challenge for companies operating in resource-intensive industries. Probably the most significant managerial challenge is finding the balance between short-term economic realities and a longterm vision of ceasing to pollute the environment. In addition, managers are under increasing pressure to demonstrate what their companies are doing for the environment and what role green innovation is playing in the solution (OECD, 2009; tinyurl.com/ana82xo).

This article examines the managerial capabilities of Interface Inc. (interfaceglobal.com), a large, US-based company that has systematically leapfrogged standard managerial routines, practices, and knowledge, and that is now recognized as a radical pioneer and green innovator.
Interface is the world's largest manufacturer of modular carpets, employing 3500 employees and selling products in over 110 countries. In 2011, Interface's net sales exceeded $\$ 1$ billion. The company operates in a resource-intensive business characterized by relatively stable operations and predictability. Radical innovation has been primarily associated with dynamic industries such as ICT and biotechnology; it is rarely associated with a traditional manufacturing industry such as carpet manufacturing. Due to the requirement for substantial start-up investments in building manufacturing facilities, the carpeting industry has a high barrier to entry and is characterized by stability, not radical change.

The carpet industry makes an interesting target for the study because it has a substantial impact on the environment. The industry disposes of five billion pounds of old carpets annually in the US (Anderson and White, 


\section{Green, Innovative, and Profitable: A Case Study of Managerial Capabilities}

Tommi Lampikoski

2009; tinyurl.com/an74uv4), and it is highly dependent on petroleum-based fuels in production. Therefore, it can be viewed as an unexpected suspect in contributing a proactive innovator that excels in corporate sustainability and radical green innovation. Not long ago, most managers perceived "going green" as a threat to their existing business, an isolated set of ecological activities, or something that increases costs with little payoff. Moreover, some managers associate greening as a clever marketing trick to polish their corporate brands (Delmas and Burbano, 2011; tinyurl.com/akwukfe). This study asks "what kind of managerial capabilities are required to create and manage a systematic flow of truly radical green innovations?" The capability perspective is chosen because dynamic managerial capabilities are needed to cope with and make sense of the rapidly changing business environments and to create new innovations (Teece et al.,1997; tinyurl.com/ax9etfx).

This article is based on an analysis of transcribed interviews with the managers of Interface as well as on secondary data including content from websites, scientific and practice-oriented journals, and company reports. Interface's experiences are widely documented in the literature, yet prior studies remain silent on the types of radical green innovations commercialized and which managerial capabilities were needed in managing innovation. This article reviews relevant concepts and illustrates Interface's organization activities and portfolio of radical green innovations. It concludes by presenting three critical managerial capabilities required in managing radical green innovations and discusses the findings and their implications for practitioners and academics of corporate sustainability.

\section{Corporate Sustainability and Radical Green Innovations}

Corporate sustainability is a company's environmental action motivated by a variety of influences within a company's market and social domains, including considerations of business performance. A review of the literature of corporate sustainability reveals that considerable scholarly effort has been devoted to identifying the drivers of corporate ecological responsiveness and in debating whether businesses can gain competitive advantage through improved environmental behaviour. An organization's environmental competitiveness derives from a dynamic and innovative response to environmental issues that is encouraged by a supportive regulatory regime (Porter and van der Linde, 1995; tinyurl.com/c9ypj92). Hart (1995; tinyurl.com/c2opdr6) argues that sustained competitive advantage is likely to be rooted in developing environmentally orientated resources and capabilities that can simultaneously improve a company's economic performance.

Companies operating in resource-intensive businesses have been recognized as engines of change in pursuing and solving various climate change issues (Hawken et al., 1999; tinyurl.com/cvx4qfl). These global harms include the annual overuse of natural resources and increased greenhouse gas emissions. The solution to climate change is suggested to rely on companies' capacity for green technological development and innovation, and reducing the current environmental burden in a quick and sufficient way requires companies to redirect their focus of innovation. Azzone and colleagues (1997; tinyurl.com/angr2eh) suggest that companies may choose either a passive lobbying-based green strategy or an innovation-based green strategy. The latter strategy views the environmental variable as the most important competitive priority and seeks to introduce new technologies that radically improve the environmental performance of current technologies, and to create new market opportunities as a consequence of environmentally friendlier product innovations.

Choosing and implementing an innovation-based green strategy calls for understanding relevant concepts such as green innovation. Managers may ask how to define this concept and in what ways green innovation differs from traditional innovation. In prior research, green innovation refers to "new or modified processes, techniques, practices, systems and products to avoid or reduce environmental harms" (Beise and Rennings, 2005; tinyurl.com/b4npep7). This broad definition includes all the changes in the product portfolio or in the production processes that address sustainability targets. Therefore, it refers to an innovation that addresses waste management, eco-efficiency, and any other action implemented to reduce the company's environmental footprint. This definition is based on the effect of the innovation activities independent of the initial intent and novelty of innovation. That is, it includes both incremental and radical improvements.

In addition, prior research suggests that green innovation differs from traditional innovation and is a separate sub-group of innovation with a primary focus on reducing or avoiding harm to the environment (CarrilloHermosilla et al., 2010; tinyurl.com/aafz83d). First, green innovation is not an open-ended concept as it characterizes innovation that explicitly stresses the reduction of environmental footprints, whether intended or not (OECD, 2009; tinyurl.com/ana82xo). Second, it creates pos- 


\section{Green, Innovative, and Profitable: A Case Study of Managerial Capabilities}

Tommi Lampikoski

itive externalities by providing knowledge during the research and innovation phases, and it then reduces environmental effects and generates externality in the diffusion phase, which can also be socially desirable. Green innovation can entail alteration of social norms, cultural values, and institutional structures (Rennings, 2000; tinyurl.com/b7ltg2n).

As previously suggested, green innovation should be discussed in conjunction with the novelty of innovation. O'Connor and Ayers (2005; tinyurl.com/anx72bo) define radical innovation as "the commercialization of products and technologies that have strong impact on the market, in terms of offering wholly new benefits, and the firm, in terms of its ability to create new businesses". These impact levels are correlated with high risk and high uncertainty in the firm, requiring it to develop new, situation-specific competencies in technology, market, and organizational domains. Radical innovations are different from incremental innovations considered as step-by-step improvements. They require more time for research and development and involve greater risk for market adoption; yet, they can yield a considerable positive impact on a firm's profitability as well as to industry and economic dynamics.

Radical innovations can alter, redefine, or rejuvenate existing industries by de-maturing declining technologies, or they can result in the emergence of new industries. The development of new businesses and product lines based on radical innovations, which are essential for the renewal of a company's competitive position, require management practices that differ substantially from those required for incremental innovation. Therefore, radically new products and business models involve the development or application of significantly new technologies; require considerable behavioural changes to existing markets; and require new skills, abilities, and systems throughout the organization. However, gaining support for radical initiatives can be demanding in companies where internal cultures and pressures favour low risk and immediate rewards from step-by-step improvements (O'Connor and Ayers, 2005; tinyurl.com/anx72bo).

\section{Organizing for Green Innovation at Interface}

In 1994, Ray Anderson, CEO and founder of Interface Inc., decided to embrace sustainability as a new primary strategy for the company. According to Anderson's vision, corporate sustainability would serve as a source of competitive advantage that could provide the firm with access to new markets, assist it in building new skills and competencies, and help the company pioneer market-winning radical green innovations (Anderson et al., 2010; tinyurl.com/abn2aab). However, the vision received initial resistance from managers, because at the time there was a shortage of corporate sustainability frameworks and prior success stories, scarcity of economically viable green technologies, and a lack of a "burning platform" for catalyzing a major strategic change.

Since 1996, Interface chose to adopt an innovationbased green strategy. Resource-intensive businesses, such as Interface, which operates in the carpet industry, are not obvious radical, green product innovators, because they mainly focus on achieving cost savings through operational efficiency. Prior research has emphasized the importance of technological and organizational capabilities in stimulating green innovations in manufacturing firms (Horbach, 2008; tinyurl.com/avta25m). However, Kesidou and Demirel (2012; tinyurl.com/bjjpq63) argue that firms differ by their capabilities and respective strategies for green innovation. Less innovative companies adopt green innovation to reduce production costs and comply with the minimum environmental standards, while more innovative companies adopt green innovation to enter new markets.

How did Interface's senior management cultivate the initiation of radical green innovations? Initially, the environmental vision and strategy took form through the development of a "7 Fronts of Sustainability" guideline. This guideline was crafted by the CEO, a small group of managers, and the Eco Dream Team, which was an external group of green business professionals. The initiative was pursued and supplemented by two supporting programs: QUEST and EcoSense. The QUEST program focused on eliminating all forms of waste from operations. Initially, top management set an ambitious goal to gain a 50 percent cost reduction in the first three years. The EcoSense program analyzed manufacturing processes in terms of the impact of each step on product quality, process efficiency, and their environmental impact, and it covered as many as 400 initiatives by 1997 .

Next, Interface merged QUEST and EcoSense by forming 18 cross-functional teams with an assigned scope of investigation and implementation ranging from waste elimination to toxic material reduction. A Global Sustainability Council stimulated cross-functional development and rapid global scaling of ideas. In addition, Regional Innovation Officers and the Chief Innovation 


\section{Green, Innovative, and Profitable: A Case Study of Managerial Capabilities}

Tommi Lampikoski

Officer facilitated a systemic and global exchange of talent, ideas, and best practices across global manufacturing locations. The guideline provided the firm with interesting results, many of them considered as incremental improvements forming a path towards industrylevel change. Nonetheless, progress through incremental innovations proved to be too slow to make a radical environmental impact. In 2006, the Mission Zero program replaced the 7 Fronts of Sustainability guideline, with the goal of creating the first large-sized industrial firm with zero environmental footprint by 2020 .

For Interface, the growth of markets for environmentally friendlier products accelerated with a growing base of loyal business customers who valued environmentally friendlier carpets. However, the green alternative was adopted only if it offered a compelling price point, equal-to-superior performance, and quality/durability. The company's sustainability strategy opened an access to new green innovations and markets. For example, Interface gained a differentiation advantage by pioneering a carpet manufactured using only solar energy. To accomplish these achievements, Interface had to construct radical innovation competencies, meaning the ability of a firm to successfully commercialize radic- al innovations repeatedly and across organizational settings (O'Connor and Ayers, 2005; tinyurl.com/anx72bo).

\section{Interface's Portfolio of Radical Green Innovations}

Interface's initial 7 Fronts of Sustainability and the new Mission Zero program addressed breakthrough innovations in multiple areas. These included: i) pioneering systemic innovation enabling the recycling and reuse of end-of-life carpets, and thus enabling the introduction of sustainably sourced materials and carpets; ii) radical elimination of toxic and petroleum-based fuels, chemicals, and materials; and iii) designing new radical product innovations based on the principles of corporate sustainability. Figure 1 illustrates a sample of radical, first-to-industry innovations pioneered by Interface between 1996 and 2012. It highlights the company's commercialized product and service innovations as well as its process and material innovations. These innovations were crafted and studied using the information from interviews with the firm's managers and secondary material consisting of publicized case studies and reports on Interface. For examples of these innovations, see the Interface website: tinyurl.com/b59o9pq.

\section{Product and service innovations}

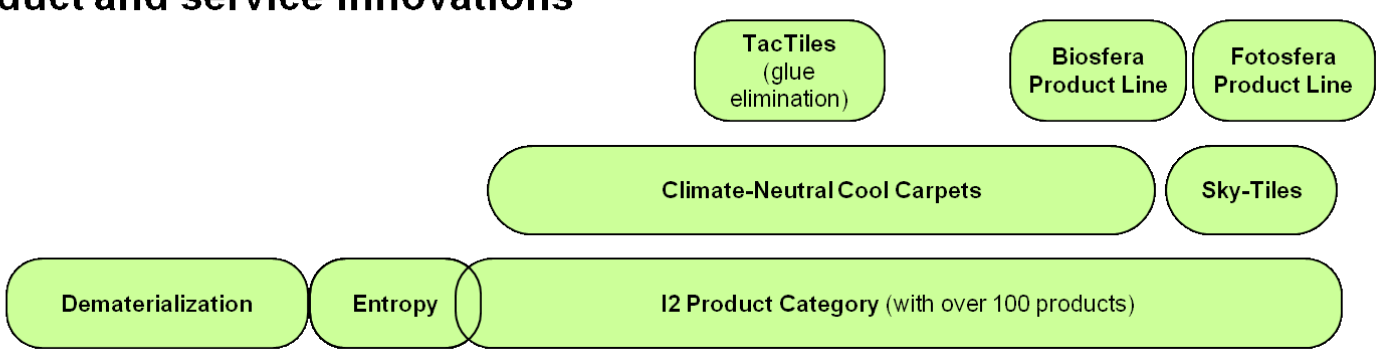

\section{Process and material innovations}

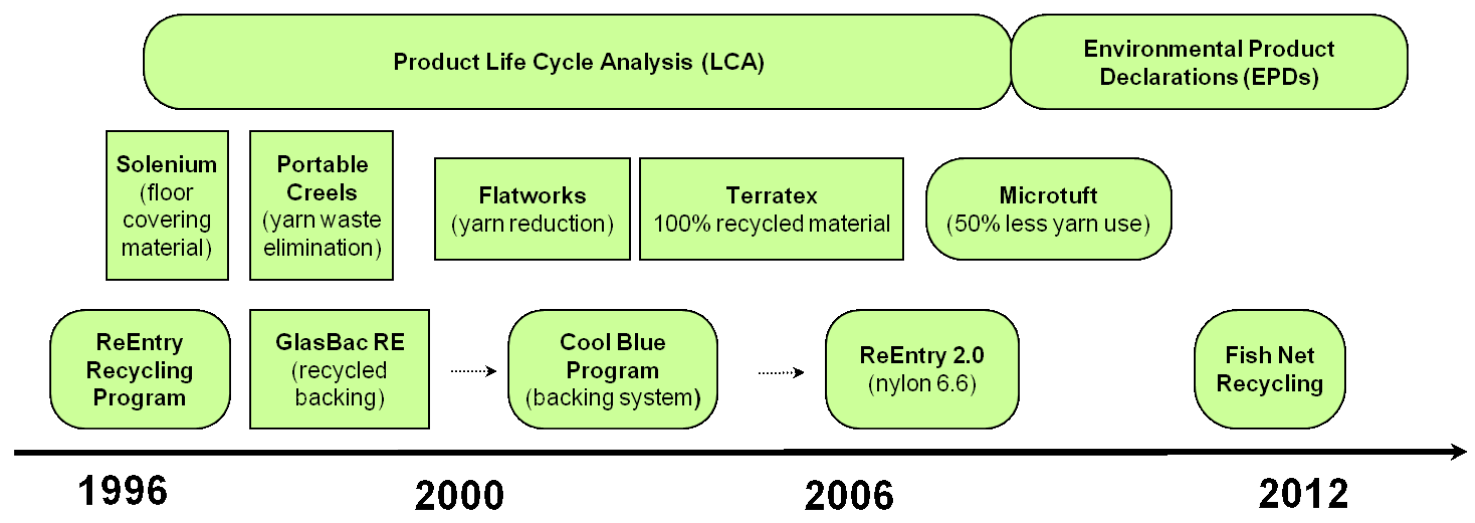

Figure 1. Interface's first-to-industry green innovations 


\section{Green, Innovative, and Profitable: A Case Study of Managerial Capabilities}

Tommi Lampikoski

These pioneering, green innovations exemplify that companies going green are constantly required to launch a wide range of transformative innovations across their business operations over a long period of time. Interface's innovations assisted the company in its quest to introduce industry breakthroughs in strategically important areas and helped it to gain commercial success. The key innovations are further discussed in the following sections.

\section{Product and Service Innovations}

Entropy (tinyurl.com/amz79pz) is an innovative carpet model inspired by the asymmetrical, random patterns found in nature. After its launch in 2000, it rapidly became a best-seller; faster than any other product in the company's history. Entropy inspired the creation of the i2-product category, stimulating the commercialization of over 100 sub-products and reaching sales of $\$ 130$ million by 2009. In 2003, Interface pioneered climate-neutral Cool Carpet, zeroing out all greenhouse gas emissions associated with the entire lifecycle of a manufactured carpet.

TacTiles, a carpet tile installation product, was introduced in 2006 and its innovative design was inspired by the sticky pads of a gecko. The toes of the lizard have a special adaptation that allows them to adhere to most surfaces without the use of liquids or surface tension. In addition, the tiles are stuck to each other, not to the floor, and their collective weight holds them down due to gravity as nature would do. Therefore, TacTiles eliminated the use of glue in carpet hard floor installation, enabled the full-recycling of end-of-life carpets and opened access to new commercial and residential markets. Interface sold about 15 million TacTiles in 2008 alone. In 2011, the Sky-Tiles carpet product opened access to a new market, commercial airplanes, through a five-year development project with Boeing.

In 2011, the company introduced Biosfera, which is a carpet made of $100 \%$ recycled yarn (tinyurl.com/aq6u3s6), making it the most sustainably produced carpet launched to date. Soon after, another carpet tile product was launched: Fotosfera tiles (tinyurl.com/ bboz3td) are made from yarn with 63 percent bio-based content, meaning that they use oil from the seeds of the castor bean plants.

\section{Process and Material Innovations}

To decrease the need for petroleum-based raw materials in manufacturing, the company introduced several process innovations. First, breakthroughs in process innovations include Flatworks, which reduces the need for yarn material by about 50 percent and the Cool Blue system, which eliminates the use of virgin vinyl in backing produced by the manufacturing line. Material innovations include Terratex fabric, the industry's first post-consumer recycled polyester fabric, which is fully recyclable and renewable. Moreover, Interface pioneered the Life Cycle Analysis (LCA) method, which analyzed the environmental footprint of products and processes from raw materials to final disposal. As a follow-up program of LCA, Interface recently introduced Environmental Product Declarations (EPD), which are based on ISO 14025 guidelines for transparency. EPDs are similar to nutrition labels found on food products; they display a carpet product's ingredients as well as the environmental impacts of the raw materials and manufacturing processes (tinyurl.com/bkxp5np).

In 2007, after a decade's worth of experimentation, Interface partnered with an Italian nylon recycler to pioneer the ReEntry 2.0 program, which enabled it to fully recycle any manufacturer's carpets. This was a major improvement because the original ReEntry program introduced in 1996 allowed for only partial recycling of the end-of-life carpets. Moreover, the company partnered with Aquafil to turn discarded fish nets into new carpet tiles. Such green innovation necessitates long development cycles, substantial financial investments, and risk-taking related to materials, business models, and technologies. Nevertheless, Interface's experiences exemplify that not every radical innovation result in commercial success. For example, the company had a letdown in launching a new business model called Evergreen Lease, which was based on leasing carpets to customers with a service agreement. Then there was Solenium, a lightweight, composite floor covering containing no nylon; this material innovation lacked long-term durability and was therefore a market failure. Further, Interface made a failed multi-million dollar investment in a technology to recycle nylon 6.6 that never succeeded.

On the other hand, Interface's green product portfolio highlights three company-perceived benefits. First, Interface earned intangible benefits in terms of goodwill and corporate image in the marketplace. Second, Interface created new product innovations such as Entropy, revealing new revenue streams and differentiation opportunities. Third, new insights unlocked interconnected sources of savings. By reducing the weight of a carpet by just an ounce per square yard, the company, which sells millions of yards of carpet annually, consid- 


\section{Green, Innovative, and Profitable: A Case Study of Managerial Capabilities}

Tommi Lampikoski

erably reduced its use of petroleum-based raw materials and chemicals. Furthermore, through dematerialization, Interface received savings in energy and water use, paid less for shipping, and reduced its greenhouse gas emissions. Interface's designer, David Oakey, said: "Reducing the face weight of a US carpet tile by a one ounce per square yard - about four percent - would save half the amount of energy needed to operate an entire American carpet tile factory" (Anderson 2009; tinyurl.com/an74uv4). Since 1994, Interface has decreased the average face weight of their carpet tile by more than four ounces per square yard.

Through sustainability programs, including the Mission Zero strategy, Interface has doubled its earnings, sold 146 million square metres of carpet that was manufactured using climate neutral processes, cut 82 percent of its greenhouse gas emissions (relative to sales), reduced its landfill waste by 77 percent, and reduced fossil fuel consumption by 60 percent. Interface's cumulative waste savings since 1995 equate to \$433 million (tinyurl.com/ayuoyfs). However, a new level of radical problem solving is needed to reach Mission Zero program's goals because Interface continued to release 162 tons of regulated air pollution, 59 tons of acid-rain-producing pollutants, and 142 tons of smog-generating photochemical pollutants in 2009 (Anderson and White, 2009; tinyurl.com/an74uv4). The next breakthroughs in sustainability may require a more open approach to ignite innovation, thus opening avenues for further research on how open-innovation networks for green innovation are orchestrated in resource-intensive businesses.

\section{Three Managerial Capabilities}

To succeed in creating a steady stream of breakthrough innovations, Interface needed to develop a set of new managerial capabilities for radical innovation. Prior research suggests that in order for companies to achieve and sustain a competitive advantage, they need to establish and nurture dynamic capabilities to cope with rapidly changing environments (Teece et al., 1997; tinyurl .com/ax9etfx). These managerial competencies include sensing (the identification of opportunities and threats), seizing (the mobilization of effective resources to deliver value to shape markets and customers), and reconfiguring capabilities for enabling continuous renewal.

This study contributes to innovation capability research by illustrating three critical managerial capabilities specific for radical green innovations based on the insights gained from the interviews with managers of
Interface, company presentations, and an extensive literature review. Each capability reflects a unique purpose, task, and set of skills, as well as outcomes. These managerial capabilities are principally not consecutive, separate capabilities; rather, they evolve together as a combined set (Table 1).

The Research capability makes sense of the emerging sustainability paradigm by helping the firm to gain a holistic understanding of corporate greening. It assists in seeking inspiration and understanding of how to adopt and apply radically different corporate sustainability frameworks and design principles into the innovation development. The Research capability encourages managers to examine how other disruptive green innovators have connected sustainability with core innovation activities. It helps them in seeking out ways to unlock revolutionary green thinking through new frames and design rules, by exploring new paths to discovery, and by identifying potential ways of managing radical green innovations inside and outside their companies.

Ultimately, this relentless search focuses on identifying potential routes to connect green innovation to a manager's unique corporate context and industry setting, by giving a holistic picture of the emerging business paradigm, and by linking innovation to core strategy and business operations. As Interface's experiences indicate, the Research capability supports a long-term, persistent hunt for radically different, environmentally friendlier raw materials, and the need to identify radical ways to eliminate dependence on petroleum-based raw materials. Managers typically ask and solve "why" questions to make sense of how radical ideas contribute to solving the holistic, interrelated, and complex challenges of running an environmentally responsible business. Interface's renewed approach to its waste management illustrates the usability of the research capability. It allowed Interface's management and staff to rethink and research waste streams through novel perspectives, as directed by the CEO Anderson, who redefined the waste as any cost that does not add value to customers. The renewed thinking transformed the prior "take-make-waste" approach to view carpet waste as a valuable, renewable, and reusable raw material that has substantial cost-saving potential.

The Recognize capability refers to recognizing opportunities by building on the insights gained in research activities. It helps management to identify the missing pieces of the puzzle by recognizing new business oppor- 


\section{Green, Innovative, and Profitable: A Case Study of Managerial Capabilities}

Tommi Lampikoski

Table 1. Managerial capabilities for radical green innovation

\begin{tabular}{|c|c|c|c|}
\hline & \multicolumn{3}{|c|}{ Managerial Capabilities } \\
\hline & 1. Research & 2. Recognize & 3. Revolutionize \\
\hline Purpose & $\begin{array}{l}\text { Make sense of the emerging } \\
\text { paradigm. }\end{array}$ & - Recognize the missing pieces. & $\begin{array}{l}\text { - Connect and scale the } \\
\text { emerging dots. }\end{array}$ \\
\hline Tasks & $\begin{array}{l}\text { - Facilitate investigative } \\
\text { curiosity through experimental } \\
\text { re-engineering and reframing } \\
\text { of challenges. } \\
\text { - Borrow from nature's design } \\
\text { principles. } \\
\text { - Observe and look inside and } \\
\text { outside the company for } \\
\text { sources of radical ideas. } \\
\text { - Search and discover new and } \\
\text { unknown ways of doing things. }\end{array}$ & $\begin{array}{l}\text { Identify partners, suppliers, } \\
\text { and stakeholders best } \\
\text { equipped to fill the identified } \\
\text { gaps with complementary } \\
\text { skills, brands, and talent. } \\
\text { - Identify senior leaders with } \\
\text { respected track records and } \\
\text { power to prioritize the radical } \\
\text { experiments. } \\
\text { - Discover emerging innovation } \\
\text { opportunities and gaps across } \\
\text { the emerging value system. }\end{array}$ & $\begin{array}{l}\text { - Connect the strategy, } \\
\text { entrepreneurial leadership, } \\
\text { and environmental vision } \\
\text { with a continuous flow of } \\
\text { radical green innovations. } \\
\text { - Seck answers to "what if" } \\
\text { questions and push the } \\
\text { boundaries of what is } \\
\text { possible. } \\
\text { - Eliminate old-fashioned } \\
\text { industrial recipes and } \\
\text { practices. }\end{array}$ \\
\hline Critical question & $\begin{array}{l}\text { Are we able to make sense of } \\
\text { the emerging green business } \\
\text { paradigm? }\end{array}$ & $\begin{array}{l}\text { Do we possess the capable } \\
\text { talent to design, develop, and } \\
\text { cultivate the next wave of } \\
\text { radical green innovations? }\end{array}$ & $\begin{array}{l}\text { - Can we revolutionize the } \\
\text { existing industrial system } \\
\text { through radical green } \\
\text { innovation? }\end{array}$ \\
\hline Outcome & $\begin{array}{l}\text { - Holistic understanding of how } \\
\text { the environmental system } \\
\text { works and how it is connected } \\
\text { to strategy, leadership, and } \\
\text { heart of innovation activities. } \\
\text { - Collection of novel principles, } \\
\text { values, and frameworks to } \\
\text { apply across business } \\
\text { functions. }\end{array}$ & $\begin{array}{l}\text { - Established foundation for a } \\
\text { strategic breakthrough } \\
\text { innovation program, } \\
\text { supported by senior leaders. } \\
\text { - A talent and resource pool } \\
\text { supported by an open network } \\
\text { capable of making a difference. }\end{array}$ & $\begin{array}{l}\text { - Culture of environmental } \\
\text { leadership, experimentation, } \\
\text { and innovation. } \\
\text { - Systematic flow of differing } \\
\text { radical innovations. } \\
\text { - Competitive advantage } \\
\text { through new profits, and } \\
\text { access to new markets and } \\
\text { differentiation. }\end{array}$ \\
\hline
\end{tabular}

tunities and identifying potential gaps and weaknesses within the existing industrial system. Managerial tasks related to the Recognize capability include identifying respected senior leaders to cultivate the green initiatives, identifying potential market size for green products, establishing business cases for radical innovations, and pinpointing potential risks and internal weaknesses. Further, managers seek the right partners and stakeholders who are capable of making a difference and filling in the identified gaps. This capability addresses a type of activity that can result in either failure or success depending on whether managers are able to locate, motivate, and attract internal and external talent that is capable of radical innovation. This type of talent is not afraid to put its face and reputation on the line, has a respected track record, and is capable of making things happen.

The combined outcomes of the Research and Recognize capabilities are likely to result in establishing a foundation and a platform consisting of continuous learning, guiding values, and principles for the design and realization of radical green innovations with capable internal and external networks. Managers typically ask questions such as "who can make a difference?" For Interface, initial research and analysis of its corporate-level waste footprint indicated a shocking result: 10 percent of sales, (70 million dollars) were going down the drain as by-product waste (Anderson and White, 2009; tinyurl.com/an74uv4). This insight led to the strategic ur- 


\section{Green, Innovative, and Profitable: A Case Study of Managerial Capabilities}

Tommi Lampikoski

gency of eliminating waste from all operations by means of recognizing the right external expertise to educate and assist Interface staff in waste elimination. Furthermore, Interface proceeded to recognize the most critical sources and bottlenecks of waste streams and ideated how the waste streams could be reused, recycled, repurposed, and eliminated.

The Revolutionize capability enables managers to connect all of the pieces of the emerging green-business paradigm and set radical ideas as a corporate priority. With the help of this capability, radical green innovations are integrated deeply into the heart of the vision, strategy, culture, and entrepreneurial leadership. Managers and "intrapreneurs" (tinyurl.com/nvs5wb) aim to commercialize a holistic flow of radical initiatives that fill in the identified gaps and solve the problems, as the perspective of "how to do things around here" is radically altered. This capability supports a phase of evolution in which managers seek radical answers to questions about how to revolutionize the existing industrial system via particular radical green ideas. These questions typically lead to dialogue, debate, new insights, innovative partnerships, and renewal through constant learning.

Respected senior leaders set ambitious development targets and provide "permission to pursue", thus giving freedom to push beyond existing boundaries, to experiment and have permission to fail, as well as learn and build on momentum for successful cases. By asking "what if?" and "how can our products and services help in healing the environment?", managers unlock new revolutionary ideas that potentially make the prior knowhow, technologies, and ways of operating obsolete. The Revolutionize capability leads to a realization and flow of different types of radical green innovation, offers competitive advantage and differentiation opportunities, and opens access to new markets and revenues. Ultimately, it results in the emergence of companies capable of conducting business with zero environmental footprint. That is, even large global firms can produce zero waste and emissions, be powered by 100 percent renewable energy, develop climate-neutral to climate-positive products, and operate via a closed loop manufacturing system. For Interface, the company's success in waste elimination started to result in radically different ways to design, manufacture, and innovate new products. Through the Revolutionize capability, Interface is currently progressing towards a zero waste goal, enabled by a closed loop manufacturing sys- tem ("borrow-make-return") and a series of incremental and radical innovations.

Is zero environmental footprint just an ideological vision or a de facto view of how all companies will operate in the near future? The interviewed managers and other research material uniformly suggest that most largesized firms are beginning to apply one or two of the managerial capabilities identified in this study, but only a few companies, such as Interface, excel in advancing all three. These differentiating and hard-to-imitate managerial capabilities helped Interface to shape the entire industry and gain a winning position through radical green innovation. Furthermore, this study illustrates that managers capable of navigating successfully between the identified capabilities can potentially make better sense of the emerging green business paradigm, can contribute to solving some of the world's environmental challenges by seizing emerging business opportunities, can disrupt deeply rooted knowledge and industrial practices, can and consequently succeed in "doing well by doing good".

\section{Conclusion}

One way companies integrate environmental concerns into their strategies while consolidating their competitive advantage is through green innovations. Interface's 17 years of progress in corporate greening illustrate that even an incumbent operating in a traditional manufacturing industry can reach substantial competitive advantage through green innovation. Radical green innovation in terms of launching first-to-the-industry green products and sustainable process breakthroughs provided the company with cost savings, access to new markets, and increased sales and revenues. Interface's experiences suggest that firms can maximize the benefit of corporate sustainability by focusing on radical green innovation. However, this approach necessitates the establishment of three managerial capabilities that allow the company to continuously research, recognize opportunities, and revolutionize the industry. Top management and sustainability managers lead the building and nurturing of these capabilities, yet all managers across the company must focus on the constant navigation between these capabilities, and a lack of experience in one capability domain can prohibit success in others. In sum, these capabilities enable managers to better cultivate, manage, and realize radical green innovations in their quest to become more sustainable companies. 


\section{Green, Innovative, and Profitable: A Case Study of Managerial Capabilities}

Tommi Lampikoski

\section{About the Author}

Tommi Lampikoski, MSc (Econ), is a visiting scholar at the Haas School of Business, University of California Berkeley, USA, and a project researcher at the School of Business, Aalto University, Finland. He acts as a project manager in a joint research project with the Finnish Funding Agency for Technology and Innovation and FIMECC's Innovation \& Network consortium. His ongoing doctoral research focuses on the management of radical green innovation and his current research interests include open innovation, corporate sustainability, and green business strategies in resource-intensive businesses. He is an author of three business books in the fields of creativity, green business, and innovation management. He previously held various managerial positions in the ICT industry in Finland.

Citation: Lampikoski, T. 2012. Green, Innovative, and Profitable: A Case Study of Managerial Capabilities at Interface Inc. Technology Innovation Management

Review. November 2012: 4-12. 